\title{
ESTRATÉGIAS DE ENFRENTAMENTO ADOTADAS POR MULHERES VIVENDO COM HIV/AIDS: UMA REVISÃO SISTEMÁTICA
}

\author{
COPING STRATEGIES ADOPTED BY WOMEN LIVING WITH HIV/SIDA: A \\ SYSTEMATIC REVIEW
}

\author{
Olga Caroline Pereira dos Santos Miranda ${ }^{1}$, Josabel de Souza Dourado Oliveira', \\ Técia Maria Santos Carneiro e Cordeiro².
}

Faculdade Anísio Teixeira - FAT ${ }^{1}$, Universidade Federal da Bahia - UFBA².

\begin{abstract}
The Syndrome of Immunodeficiency Acquired (SIDA) is a disease that can trigger off sentiments of fear and guilt in people living with HIV and, consequently, disorganize their social relations. The objectives of this study were to evaluate in the Brazilian scientific literature the coping strategies adopted by women living with HIV/SIDA and describe the contributions of these coping strategies for a adaptation and acceptance of the disease by women. This is a systematic review. The search of the data was realized in electronic data bases in SCIELO and LILACS. The data analysis was carried out three thematic categories on the basis content analysis from Bardin. The woman in dealing with the discovery SIDA has been influenced by stereotypes departing from company, affecting their sexual life and social relations. The impact of this discovery reflect the stigma of this woman during her fellowship in society. The main coping strategies of women front living with HIV/SIDA run through health professionals, family, religiousness and work, these fundamental elements for the adaptation and acceptance of living with the virus and/or disease. And for this adaptation with reality makes it possible for the woman to continue life in society, it is necessary that the counseling be with trained health professionals.
\end{abstract}

Key words: Women's Health, Acquired Immunodeficiency Syndrome, Adaptation Psychological, Peer Review.

\section{Resumo}

A Síndrome da Imunodeficiência Adquirida (AIDS) é uma doença que pode desencadear sentimentos de medo e culpa nas pessoas soropositivas e desorganizar suas relações sociais. Os objetivos deste estudo foram avaliar na literatura científica brasileira as estratégias de enfrentamento adotadas por mulheres vivendo com HIV/AIDS e descrever as contribuições destas estratégias de enfrentamento para a adaptação e aceitação da doença pelas mulheres. Trata-se de uma revisão sistemática. A busca dos dados foi realizada nas bases de dados eletrônicas da SCIELO e LILACS. A análise dos dados foi realizada por três categorias temáticas segundo a análise de conteúdo de Bardin. A mulher ao lidar com a descoberta da AIDS acaba sendo influenciada por estereótipos, que partem da sociedade, comprometendo sua vida sexual e suas relações sociais. Os impactos desta descoberta refletem o estigma dessa mulher durante seu convívio na sociedade. As principais estratégias de enfrentamento das mulheres frente à vivência com HIV/AIDS perpassam os profissionais da saúde, os familiares, a religiosidade e o trabalho, elementos estes primordiais para a adaptação $e$ aceitação da vivência com o vírus e/ou doença. $E$ para que esta adaptação com a realidade possibilite para a mulher a continuidade da vida na sociedade é necessário que o aconselhamento seja com profissionais de saúde capacitados.

Palavras chave: Saúde da Mulher, Síndrome da Imunodeficiência Adquirida, Adaptação Psicológica, Revisão. 


\section{Introdução}

A Síndrome da Imunodeficiência Adquirida (AIDS) é o estagio mais avançado da doença causada pelo Vírus da Imunodeficiência Humana(HIV), que ao estar presente no organismo, torna o indivíduo soropositivo. Essa doença compromete o sistema imunológico, deixando o corpo fragilizado e vulnerável a diversas patologias. $O$ primeiro caso relatado no Brasil ocorreu na década de 80 , marcado por uma epidemia, em que homens eram mais afetados que mulheres, relatando uma estimativa de seis homens para uma mulher ${ }^{1}$.

Houve uma considerável diminuição dos casos de AIDS a partir de 1997, após a implantação da Terapia Antirretroviral , em 1996, que reduz a carga viral do portador do vírus. Além da implantação dessa terapia, surgiram também programas de controle do HIV/AIDS, de prevenção deste agravo, detecção precoce e promoção na Atenção Básica à Saúde com o intuito de efetivar a integralidade do enfrentamento desta doença ${ }^{2}$. O diagnóstico é obtido através, de um exame laboratorial, onde a amostra do sangue é colhida e examinada constatando a presença do vírus no organismo. Depois do diagnóstico, a AIDS pode ser tratada com antirretrovirais disponíveis gratuitamente nos postos especializados em Doenças Sexualmente Transmissíveis (DST), HIV e AIDS, porém ainda não existe cura para a doença, o que desencadeia algumas implicações na vida dos indivíduos ${ }^{1}$.

Mesmo com a considerável redução do número de casos de AIDS no Brasil, a maior causa de contágio, ainda nos dias atuais, é a relação sexual sem ouso de preservativos. Os preservativos são contraceptivos que reduzem a probabilidade de haver disseminação do vírus. Geralmente, há o uso de outros anticonceptivos como a pílula, o Dispositivo Intrauterino (DIU), os métodos injetáveis, dentre outros, no intuito de prevenir apenas uma gravidez indesejada e não considera a importância da prevenção contra as DST, expondo ambos os parceiros a um maior risco de contágio pelo $\mathrm{HIV}^{3}$.

Os casos de mulheres com AIDS vêm aumentando nos últimos anos, sendo 1,7 casos em homens para cada mulher. Alguns dos fatores que têm contribuído para essa elevação são: a iniciação precoce na vida sexual e a infidelidade dos parceiros fixos ${ }^{1}$. Tratando-se do posicionamento da sociedade frente às questões relacionadas à AIDS, percebe-se que há um julgamento de valor sobre o indivíduo portador da doença, sejam homens ou mulheres. Os portadores acabam sendo rotulados e muitas vezes evitados em situações comuns do cotidiano levando-os a restringir suas relações com o meio social. A proposta então, para os soropositivos, é lidar com essa nova realidade e enfrentá-la ressignificandovalores ${ }^{4}$.

Na vida da mulher portadora da doença não é diferente, o impacto de ser soropositiva acaba por desorganizar suas relações sociais, sendo quase sempre, estigmatizadas e alvo de preconceitos. Cada mulher elabora a sua forma de enfrentar o diagnóstico da doença, diante do impacto causado nas suas relações sociais, desde a ocultação e negação, até aprender a conviver com a realidade de sersoropositiva ${ }^{5}$.

Assim, além do medo e das angústias, a mulher tem receio de receber julgamentos morais e esconde a sua realidade para permanecer no convívio social, aumentando o sentimento de culpa evergonha ${ }^{6}$.

O enfrentamento da AIDS pela mulher é um processo em que a mesma administra as demandas que surgem com a doença, tanto em suas relações pessoais quanto nas interpessoais e aprende a lidar com as suas emoções e minimizar o sofrimento psíquico gerado nesse contexto estressor. Por isso, a necessidade de buscar estratégias que contribuam para a adaptação e aceitação da AIDS consiste num processo complexo e emblemático ${ }^{7}$.

Com base nestes argumentos, questionamos: Quais as estratégias de enfrentamento adotadas por mulheres vivendo com HIV/AIDS? Quais as contribuições destas estratégias na adaptação e aceitação da doença pelas mulheres?

Tendo em vista a mudança do cenário atual da AIDS no Brasil, o crescimento do número de mulheres acometidas, as consequências desta doença na vida das mulheres e de seus familiares, além da escassez de produções científicas publicadas em português sobre o tema, percebeu-se a necessidade de desenvolver estudos com enfoque no enfrentamento dessa doença por mulheres soropositivas. Isso se deu com o intuito de contribuir para o conhecimento científico, para os profissionais de saúde e para sociedade.

Os objetivos deste estudo são avaliar na literatura científica brasileira as estratégias de enfrentamento adotadas por mulheres vivendo com HIV/AIDS e descrever as contribuições destas estratégias de enfrentamento para a adaptação e aceitação da doença pelas mulheres. 
Metodologia

Este estudo é uma revisão sistemática, que se caracteriza como uma pesquisa que utiliza como dados, materiais científicos publicados sobre determinado tema de interesse. Uma síntese das principais evidências empíricas, em um único estudo, possibilitando auxílio literário para futuros pesquisadores e profissionais que se interessem.

A busca dos artigos foi realizada nas bases de dados da Scientific Electronic Library Online (SciELO) e na Literatura Latino-Americana e do Caribe em Ciências da Saúde (LILACS). Estas bases foram selecionadas por reunir os principais periódicos brasileiros das ciências da saúde. Foram utilizadas três palavras-chave e sinônimos em português na busca dos artigos. Para a SciELO utilizou-se a seguinte combinação: "mulheres" AND "aids" AND "enfrentamento". Na LILACS: "mulher" AND "aids" AND "enfrentamento".

Os critérios de inclusão estabelecidos foram: artigos publicados em periódicos brasileiros, no idioma português, entre os anos de 2003a 2014 e que apresentavam resultados relativos ao enfrentamento da AIDS por mulheres. Como critérios de exclusão, não foram utilizados artigos de revisão de literatura ou que apresentassem resultados de pesquisas com mulheres no período gestacional, ao considerar que ampliaria as questões tratadas neste artigo, estando relacionadas também ao feto. O período de busca dos artigos foi entre os meses de abril e maio de 2015.

Os artigos foram selecionados por dois pesquisadores independentes tendo em vista os critérios de inclusão e exclusão estabelecidos, as discordâncias foram resolvidas por consenso. Primeiro foi realizada a seleção pela leitura do título, depois pela leitura dos resumos e por fim pela leitura integral dos artigos. Após a seleção, foi desenvolvido um instrumento de coleta de dados com as seguintes informações: autor, ano, periódico, tipo de estudo, objetivos, amostras, estratégias de enfrentamento e contribuições para adaptação e aceitação da doença.

A análise dos dados foi realizada por meio da análise de conteúdo de Laurence Bardinda qual emergiram três categorias temáticas dos estudos selecionados, a saber: Impactos da descoberta da AIDS em mulheres, Sexualidade e estereótipos da AIDS na sociedade e Estratégias de enfrentamento da AIDS por mulheres.

Por se tratar de uma revisão sistemática, este estudo respeitou os aspectos éticos e legais dos direitos autorais de acordo a Lei no. 9.610 de 1998.

\section{Resultados e Discussão}

Foram encontrados 52 artigos, nas bases de dados, sendo 20 na SciELO e 32 na LILACS. Esses artigos foram selecionados de acordo os critérios de inclusão e exclusão, sendo excluídos os repetidos, totalizando 15 artigos. Após a leitura do resumo e do artigo completo, foram excluídos três artigos que não atenderam aos critérios estabelecidos, perfazendo o corpus documental deste estudo, 12 artigos científicos. Grande parte destes artigos foi publicada em revistas da área de enfermagem $(n=6)$, no período de 2010 a $2014(n=5)$ e com o delineamento de estudo qualitativo $(n=10)$ (Quadro 1).

\section{Impactos da descoberta da AIDS em mulheres}

Desde que foi descoberta a AIDS, as pesquisas avançaram buscando compreender as lacunas que envolvem a doença. O tratamento da AIDS tem evoluído e possibilitado o indivíduo viver bem e sem complicações. Porém, ainda há uma forte ligação da AIDS com a morte, por ser uma doença sem cura, que fragiliza o sistema imunológico e acaba por facilitar o aparecimento de outras doenças oportunistas. É importante ressaltar que, é possível ter qualidade de vida sendo soropositiva, se as medicações forem administradas corretamente, houver um suporte emocional e psicológico para essas mulheres por profissionais capacitados, e se o preservativo for utilizado de maneira regular, evitando a possibilidade de uma reinfecção.

Destaca-se que a descoberta da AIDS perpassa desde a iminência de morte até a qualidade de vida como pontos cruciais do enfrentamento desta doença frente à sociedade.Após a descoberta do diagnóstico de uma doença como a AIDS a mulher adquire sentimentos de angústia, vergonha e até mesmo o desenvolvimento de transtornos mentais como a depressão, dificuldade esta, encontrada na aceitação do diagnóstico, levando algumas mulheres a tentar suicídio, e encontrar na morte a melhor saída, sendo que estes novos sentimentos surgem com a doença trazendo várias dúvidas e incertezas sobre o futuro ${ }^{5}$.

A descoberta dessa doença torna-se maior que a dor física, diante da possibilidade eminente de morte. Sentimentos que agregam a doença acabam por desorganizar seus planos e pensamentos para o futuro, fazendo com que as 
Quadro 1. Corpus documental desta revisão sistemática. Brasil, 2003-2014.

\begin{tabular}{|c|c|c|c|c|c|c|}
\hline Número & Autor(es) & Ano & Revista & Objetivo(s) & $\begin{array}{l}\text { Delineamento do } \\
\text { Estudo }\end{array}$ & Título \\
\hline 1 & $\begin{array}{l}\text { Renesto HMF, } \\
\text { Falbo AR, Souza E, } \\
\text { Vasconcelos, } \mathrm{MG}^{6}\end{array}$ & 2014 & $\begin{array}{l}\text { Revista de } \\
\text { Saúde Pública }\end{array}$ & $\begin{array}{l}\text { Analisar o enfrentamento e as percepções } \\
\text { das mulheres em } \\
\text { relação à descoberta da infecção pelo HIV. }\end{array}$ & Qualitativo & $\begin{array}{l}\text { Enfrentamento e percepção da mulher em } \\
\text { relação à infecção pelo HIV. }\end{array}$ \\
\hline 2 & $\begin{array}{l}\text { Galvão MTG, Paiva } \\
\text { SDS }^{17}\end{array}$ & 2011 & $\begin{array}{l}\text { Revista } \\
\text { Brasileira de } \\
\text { Enfermagem. }\end{array}$ & $\begin{array}{l}\text { Analisar relatos e situações vivenciadas } \\
\text { por mulheres infectadas pelo HIV, com fins } \\
\text { de identificar suas motivações e estratégias } \\
\text { de enfrentamento frente a infecção. }\end{array}$ & Descritivo / Qualitativo & $\begin{array}{l}\text { Vivências para o enfrentamento do HIV entre } \\
\text { mulheres infectadas pelo vírus. }\end{array}$ \\
\hline 3 & $\begin{array}{l}\text { Ferreira RCM, } \\
\text { Figueredo MAC, } \\
\text { Souza } \mathrm{LB}^{18}\end{array}$ & 2011 & $\begin{array}{l}\text { Psicologia em } \\
\text { Estudo }\end{array}$ & $\begin{array}{c}\text { Entender a forma como o trabalho atua no } \\
\text { enfrentamento do convívio com o HIV/aids } \\
\text { na perspectiva de mulheres e as } \\
\text { dificuldades encontradas para a } \\
\text { manutenção do trabalho ou para a } \\
\text { recolocação profissional. }\end{array}$ & Qualitativo & $\begin{array}{l}\text { Trabalho, HIV/AIDS: Enfrentamento e } \\
\text { dificuldades relatadas por mulheres. }\end{array}$ \\
\hline 4 & $\begin{array}{l}\text { Carvalho } \mathrm{CML} \text {, } \\
\text { Galvão } \mathrm{MTG}^{5}\end{array}$ & 2008 & $\begin{array}{l}\text { Revista da } \\
\text { Escola de } \\
\text { Enfermagem da } \\
\text { USP }\end{array}$ & $\begin{array}{l}\text { Apreender como as mulheres com aids } \\
\text { enfrentam o cotidiano após o } \\
\text { conhecimento do seu diagnóstico. }\end{array}$ & $\begin{array}{c}\text { Exploratório / } \\
\text { Descritivo / Qualitativo }\end{array}$ & $\begin{array}{l}\text { Enfrentamento da AIDS entre mulheres } \\
\text { infectadas em Fortaleza - CE. }\end{array}$ \\
\hline 5 & Selli L, CechimPL ${ }^{11}$ & 2006 & Revista Bioética & $\begin{array}{l}\text { Conhecer os motivos que levam as } \\
\text { mulheres infectadas pelo HIV/Aids ao } \\
\text { silenciamento da doença, bem como } \\
\text { identificar até que ponto estabelecem } \\
\text { relação de significado entre o silêncio e a } \\
\text { saúde da coletividade. }\end{array}$ & $\begin{array}{c}\text { Exploratório / } \\
\text { Descritivo / Qualitativo }\end{array}$ & $\begin{array}{l}\text { Mulheres HIV/Aids: silenciamento, dor moral } \\
\text { e saúde coletiva. }\end{array}$ \\
\hline
\end{tabular}

Continua... 


\begin{tabular}{|c|c|c|c|c|c|c|}
\hline Número & Autor(es) & Ano & Revista & Objetivo(s) & $\begin{array}{l}\text { Delineamento do } \\
\text { Estudo }\end{array}$ & Título \\
\hline 6 & $\begin{array}{l}\text { Reis AL, Xavier } \\
\text { IDM }^{19}\end{array}$ & 2003 & $\begin{array}{l}\text { Revista } \\
\text { Brasileira de } \\
\text { Enfermagem }\end{array}$ & $\begin{array}{l}\text { Discutir a relevância do grupo de adesão } \\
\text { em relação à qualidade de vida das } \\
\text { mulheres soropositivas ao HIV, que } \\
\text { participam dessa atividade no Centro } \\
\text { Municipal de Saúde. }\end{array}$ & Descritivo / Qualitativo & Mulher e Aids: rompendo o silêncio de adesão. \\
\hline 7 & $\begin{array}{l}\text { Nascimento AMG, } \\
\text { Barbosa CS, } \\
\text { Medrado } \mathrm{B}^{12}\end{array}$ & 2005 & $\begin{array}{l}\text { RevistaBrasileir } \\
\text { a Saúde } \\
\text { Materna e } \\
\text { Infantil }\end{array}$ & $\begin{array}{l}\text { Compreender a representação social que } \\
\text { mulheres casadas, em situação de pobreza, } \\
\text { possuem acerca da AIDS. }\end{array}$ & Qualitativo & $\begin{array}{l}\text { Mulheres de Camaragibe representação social } \\
\text { sobre a vulnerabilidade feminina em tempos } \\
\text { de AIDS. }\end{array}$ \\
\hline 8 & $\begin{array}{l}\text { Martins JT, } \\
\text { Guaranhani ML, } \\
\text { Robazzi MLCC, } \\
\text { Santos } \mathrm{WC}^{15}\end{array}$ & 2008 & $\begin{array}{l}\text { Revista Gaúcha } \\
\text { Enfermagem }\end{array}$ & $\begin{array}{c}\text { Identificar junto às mulheres que estão } \\
\text { convivendo com a AIDS o conhecimento de } \\
\text { como adquiriram a doença e compreender } \\
\text { os significados de } Q V \text { para elas neste } \\
\text { momento. }\end{array}$ & $\begin{array}{l}\text { Descritivo / } \\
\text { Exploratório / } \\
\text { Qualitativo }\end{array}$ & $\begin{array}{l}\text { Significados de qualidade de vida para } \\
\text { mulheres convivendo com a AIDS. }\end{array}$ \\
\hline 9 & $\begin{array}{l}\text { Félix G, } \\
\text { CeolimMF }^{10}\end{array}$ & 2012 & $\begin{array}{l}\text { Revista da } \\
\text { Escola de } \\
\text { Enfermagem da } \\
\text { USP }\end{array}$ & $\begin{array}{l}\text { Caracterizar o perfil sócio-demográfico e } \\
\text { clínico, comportamentos em saúde, } \\
\text { crenças e atitudes sobre a doença e o } \\
\text { tratamento de mulheres com HIV/AIDS em } \\
\text { seguimento no serviço de assistência } \\
\text { especializada de um hospital universitário } \\
\text { do interior de São Paulo, e identificar } \\
\text { fatores que interferem na adesão à } \\
\text { terapêutica antirretroviral. }\end{array}$ & $\begin{array}{l}\text { Transversal / } \\
\text { Descritivo / } \\
\text { Quantitativo }\end{array}$ & $\begin{array}{l}\text { O perfil da mulher portadora de HIV/AIDS e } \\
\text { sua adesão à terapêutica antirretroviral. }\end{array}$ \\
\hline
\end{tabular}




\begin{tabular}{|c|c|c|c|c|c|c|}
\hline Número & Autor(es) & Ano & Revista & Objetivo(s) & $\begin{array}{l}\text { Delineamento do } \\
\text { Estudo }\end{array}$ & Título \\
\hline 10 & $\begin{array}{l}\text { Carvalho CML, } \\
\text { Galvão MTG, Silva } \\
\text { RM }^{9}\end{array}$ & 2010 & $\begin{array}{l}\text { Acta Paulista de } \\
\text { Enfermagem }\end{array}$ & $\begin{array}{l}\text { Apreender as alterações vivenciadas pelas } \\
\text { mulheres portadoras de Aids em decorrência } \\
\text { da infecção. }\end{array}$ & $\begin{array}{l}\text { Descritivo / } \\
\text { Exploratório / } \\
\text { Qualitativo }\end{array}$ & $\begin{array}{l}\text { Alterações na vida de mulheres com Síndrome } \\
\text { da Imunodeficiência Adquirida em face da } \\
\text { doença. }\end{array}$ \\
\hline 11 & $\begin{array}{l}\text { Sousa MCP, Santo } \\
\text { ACGE, Motta SKA }\end{array}$ & 2008 & $\begin{array}{l}\text { Saúde e } \\
\text { Sociedade }\end{array}$ & $\begin{array}{l}\text { Investigar as condições em que se têm } \\
\text { desenvolvido as práticas de prevenção do } \\
\text { HIV/Aids por parte de mulheres adultas } \\
\text { moradoras de um bairro de Teresina, situado } \\
\text { entre aqueles com maior número de casos } \\
\text { notificados da doençąa, aplicando-se ênfase } \\
\text { ao papel desempenhado nesse contexto } \\
\text { pelas relações de gênero e pela atuação do } \\
\text { Programa Saúde da Família, como estratégia } \\
\text { de atenção básica à saúde. }\end{array}$ & Descritivo / Qualitativo & $\begin{array}{l}\text { Gênero, vulnerabilidade das mulheres ao } \\
\text { HIV/Aids e ações de prevenção em bairro da } \\
\text { periferia de Teresina, Piauí, Brasil. }\end{array}$ \\
\hline 12 & $\begin{array}{l}\text { Costa P, Leite } \\
\text { RCBO }^{7}\end{array}$ & 2009 & $\begin{array}{l}\text { Revista Brasileira } \\
\text { de Cancerologia }\end{array}$ & $\begin{array}{c}\text { Identificar as } \\
\text { estratégias de enfrentamento utilizadas pelo } \\
\text { paciente } \\
\text { oncológico submetido à cirurgia mutiladora. }\end{array}$ & $\begin{array}{l}\text { Prospectivo / } \\
\text { Transversal / } \\
\text { Descritivo }\end{array}$ & $\begin{array}{l}\text { Estratégias de enfrentamento utilizadas pelos } \\
\text { pacientes oncológicos submetidos a cirurgias } \\
\text { mutiladoras. }\end{array}$ \\
\hline
\end{tabular}


mulheres renunciem a sua própria vida, para viver em função da possível morte ${ }^{14}$. A AIDS não representa mais ameaça de morte, sendo possível conviver com a doença e ter uma vida saudável por muitos anos. Os avanços tecnológicos possibilitaram ao indivíduo, e as mulheres, ter uma qualidade de vida, tanto no âmbito físico, como no psicológico e social ${ }^{15}$.

A atuação do psicólogo é fundamental nesse contexto de pós-diagnóstico da AIDS, em que a mulher geralmente torna-se vulnerável tanto às questões sociais quanto no que se refere ao surgimento de desordens emocionais e até aos transtornos decorrentes desse processo. As contribuições do psicólogo, serão em caráter individual, com aconselhamentos ou desenvolvendo atividades grupais, criando um ambiente satisfatório e promovendo qualidade de vida. Além disso, deve considerar o contexto histórico de vida para alcançar neste processo de enfrentamento a conquista individual e coletiva $^{16}$.

Compreendemos diante do corpus documental que, ao descobrir a infecção pelo vírus HIV e a presença da AIDS, as mulheres sofrem grande impacto na vida. A sensação que surge com o diagnóstico da doença é que a vida está prestes a se findar, ocorrem mudanças tanto no plano físico quanto no psicológico. Não só a doença propriamente dita, como os pensamentos e sentimentos decorrentes desse processo, acabam por desorganizar o convívio social dessas mulheres, limitando à sua vivencia a possibilidade da morte eminente. Atualmente, a expectativa de vida de soropositivos tem aumentado, não somente pela adesão ao tratamento e uso regular das medicações e preservativos, que é de grande importância nesse processo, como também pelo apoio e suporte emocional que as mulheres recebem, da religião, familiares e profissionais de saúde, promovendo assim um ambiente favorável para a convivência com a doença e, consequentemente, produzindo qualidade de vida.

Desta forma, embora o primeiro contato das mulheres seja com os profissionais da saúde, o ideal é que este processo de diagnóstico e acompanhamento seja realizado por uma equipe multidisciplinar com profissionais capacitados para auxiliar no processo de enfrentamento da mulher à doença. O psicólogo é um dos profissionais essenciais para equipes de saúde que realizam o rastreamento do HIV, por ter habilidade técnica e discernimento no momento do acolhimento da mulher diante do diagnóstico e durante o tratamento. Elaborando práticas de aconselhamento individual e atividades em grupo com a finalidade de minimizar os sofrimentos psíquicos gerados pela doença e promover qualidade de vida. Mas, os demais profissionais da equipe multiprofissional, também podem ser capacitados para tal aconselhamento.

\section{Sexualidade e estereótipos da AIDS na sociedade}

A mulher ao descobrir que tem AIDS sofre alguns impactos na vida, o primeiro deles é conviver com uma doença sem cura e, posteriormente, saber que a adquiriu através da relação sexual. A compreensão da sexualidade a partir dessa perspectiva da mulher soropositiva envolve duas dimensões: a psicológica, a mulher deverá se adaptar a uma nova fase da vida com pensamentos e sentimentos que emergem das mudanças decorrentes dessa realidade, que acabam por desorganizar a sua estrutura emocional; e a da relação com o outro, a insegurança que surge muitas vezes por ter adquirido a doença com o parceiro, sendo necessária a tomada de consciência de que é possível manter relações sexuais normalmente de forma saudável com seus parceiros fixos e/ou eventuais, fazendo sempre o uso do preservativo, evitando a possibilidade de uma contaminação ou reinfecção com o vírus HIV.

Foi possível destacar nesta categoria aspectos que envolvem dor moral, confiança no parceiro e a vivência da sexualidade. A mulher que descobre a AIDS tem uma tendência a se sentir culpada e se ausentar das relações sexuais9. A doença, que é geralmente transmitida por um parceiro, faz com que a mulher se esquive por medo de uma recontaminação ou a possibilidade de contaminar outras pessoas ${ }^{10}$. O que acaba por desorganizar suas relações sexuais fazendo-as criar um silêncio e alimentar dentro de si o retraimento que interfere diretamente no convívio com o outro e com a sociedade.

Estudiosos $^{11}$ dão mais ênfase a dor moral, motivo pelo qual elas mantêm o silêncio, fazendo-as sentir vítimas por ter adquirido a doença e ao mesmo tempo culpadas por estarem transmitindo a doença para seus filhos ou possíveis parceiros. Isso as leva, geralmente, a deixar o tratamento para evitar que a sociedade tome conhecimento da sua infecção, aumentando a probabilidade de complicações devido ao preconceito gerado em torno dessa doença. Pois, com o diagnóstico surge o medo, 
que gera na mulher esse afastamento do convívio causando uma sensação de vazio e solidão ${ }^{12}$. Quando a mulher descobre que o seu parceiro a quem confiava Ihe transmitiu a doença é como se a vida acabasse e perdesse o sentido, ela se isola, evitando manter relações sexuais, em contrapartida surge o medo de perdê-lo pelo distanciamento e acabar e ficar ainda mais sozinha.

Frente às discussões sobre a vida sexual pósdiagnóstico da AIDS nota-se que a mulher de certa forma modifica a sua estrutura, tanto na perspectiva psicológica como das suas relações com o outro. $\mathrm{O}$ vínculo afetivo e emocional com parceiro fixo, relação de confiança, está correlacionado ao medo adquirido nesse contexto. Em contrapartida, a mulher que não tem parceiro fixo sente a dificuldade de estabelecer novas relações por não confiar no preservativo e temer que isso agrave a sua condição ou possa transmitir a doença para o outro, sendo esses os principais motivos que as levam a se afastar do convívio a dois. Um dos maiores temores da mulher que tem AIDS é a maneira que a sociedade irá recebê-la, visto que ser soropositiva torna a pessoa alvo de preconceitos e discriminação. Muitas delas são rotuladas como se anulasse a existência de si mesmas, pela presença da doença, o que acaba por afastá-las do contexto social, fazendo-as ocultar a doença para não serem mais ainda penalizadas. Por isso, já não o bastante, o medo de ter uma doença sem cura, comumente ligada à morte, acaba por gerar conflitos interiores e grandes angústias, causando assim, o sofrimento das mulheres.

Os estereótipos da AIDS na sociedade abordam como aspectos importantes a discriminação, estigma, medo e angústia. Uma das principais problemáticas encontradas pelas mulheres com relação ao preconceito está relacionada ao local de trabalho. Elas ocultam o diagnóstico por medo de sofrerem com a não aceitação e discriminação dos colegas no ambiente laboral. As consequências advindas dessa circunstância e a possibilidade de um sofrimento ainda maior fazem com que estas mulheres se distanciem de pessoas próximas, que geralmente ignoram a sua condição enquanto portadora da AIDS $^{13}$.

As mulheres ocultam a doença para não serem excluídas e alvo de conceitos préconcebidos e discriminação. Visto que é uma doença que possui um histórico depreciativo e de perversão, faz com que a própria mulher ao deparar-se com o diagnóstico, crie uma sensação de impureza dentro de si. A dúvida influencia diretamente nas tomadas de decisões das mulheres, em ocultar a sua condição para esquivar-se dos possíveis rótulos e estigmas da doença, prejudicando, assim, a possibilidade de receber um suporte ${ }^{5}$.

Percebeu-se que o medo é um sentimento persistente entre as mulheres que se deparam com o diagnóstico da AIDS. A angústia de portar uma doença transmissível sem cura, e o anseio de ser rotulada, estigmatizada e isolada pela sociedade, fazem com que as mulheres silenciem o diagnóstico da doença e se retraiam guardando para si os seus temores.

\section{Estratégias de enfrentamento da AIDS por mulheres}

As relações sociais estabelecidas pela mulher portadora da AIDS são fundamentais para que possa estabelecer a forma de conviver nesse contexto ressignificando sua vida. A princípio, o serviço de saúde, é o primeiro contato que a mulher terá na descoberta da doença, é nestes serviços que devem surgir as primeiras bases de sustentação, a mulher irá receber informações acerca da infecção e encontrará apoio para lidar com a nova realidade. No ambiente familiar a mulher receberá suporte emocional, quando a família aceita e apoia, para sentir-se segura de sua condição. Muitas vezes a religião também é um ponto de equilíbrio, é por meio da fé que a mulher encontra em Deus e no sagrado, a esperança de dias melhores, diante da situação delicada. E, quando há apoio nos ambiente de trabalho, estes também, tornam-se fundamentais para que a mulher se sinta útil e produtiva.

O contexto social para o enfrentamento da AIDS por mulheres contempla a família, religião, trabalho e profissionais de saúde ${ }^{17}$. O vínculo dos profissionais de saúde para produção de confiança na paciente é muito importante, pois afasta o receio de sofrer preconceito e ser estigmatizada por causa da doença, por estes profissionais terem em seu cotidiano uma vivência mais profunda com esse tipo de diagnóstico. A família também oferece um auxílio essencial tanto no acompanhamento ao tratamento, quanto na motivação para que a mulher possa seguir em frente com seus objetivos. Os preconceitos e rótulos enfrentados tornam-se pequenos, diante do suporte recebido, principalmente quando existem filhos, onde a mulher enquanto mãe e cuidadora não despreza o seu papel de responsável pela família 
sentindo-se útil. A religião atua como conforto e alívio para as mulheres. Esperança a mais diante dessa circunstância, de que alguma divindade venha em seu socorro, trazendo consigo a expectativa de cura. Motivação interior por meio da fé contribui para que as mulheres possam aderir melhor ao tratamento e, assim, ter uma melhor qualidade de vida ${ }^{10}$.

O trabalho de um modo geral, além de um suporte financeiro é o local onde são demonstradas as habilidades, faz com que a mulher se sinta útil e independente, elevando assim a sua autoestima ${ }^{18}$. É no trabalho que a mulher vai obter a válvula de escape para os seus pensamentos sobre a doença, sendo uma das principais formas de conviver de maneira saudável com a AIDS. É notória a importância dos grupos de adesão, o conjunto de profissionais de saúde, que juntos, visam o bem estar da mulher portadora da AIDS, não apenas de maneira individual, mas também, nas abordagens coletivas $^{19}$. Com o compartilhamento de experiências e o apoio profissional as mulheres tornam-se mais confiantes e, consequentemente, aderem melhor à terapêutica. Pois, serviços de saúde não especializados e com profissionais sem capacitação compromete tanto as questões éticas quanto torna a situação como um estigma institucional $^{6}$

A família é a base motivadora que impulsiona a mulher a encarar os seus medos, aderir ao tratamento e buscar qualidade de vida. A fé também vem como conforto e suporte do sagrado, que produz paz em seu interior em meio às angústias da doença. Por fim, é o trabalho que possibilita a mulher continuar ativa, ao demonstrar suas habilidades, elevando a sua alta estima e promovendo um esvaziamento de pensamentos preocupantes com relação à doença.

\section{Conclusões}

Diante dos resultados percebeu-se a escassez de publicações acerca da temática nas bases pesquisadas, principalmente na área de psicologia, ao considerar o suporte social e psicológico importante para o enfrentamento de uma doença como a AIDS. As pesquisas se concentraram na área da enfermagem, o que corrobora com a necessidade de maiores investimentos em pesquisas acerca da atuação do psicólogo no tratamento da AIDS em mulheres, por este profissional ser um facilitador deste processo de enfrentamento.
As estratégias de enfrentamento adotadas por mulheres vivendo com HIV/AIDS observadas no presente estudo foram àquelas relacionadas ao contexto social de sua vida que envolve o contato/acolhimento dos profissionais de saúde, o apoio familiar, a religiosidade e o processo de trabalho que contribuem positivamente neste processo de adaptação e aceitação da vivência com o vírus e/ou doença. O contato da mulher é, geralmente, com a equipe multidisciplinar de saúde, principalmente psicólogos, os quais exercem um papel de extrema importância e confiança no momento do acolhimento para aceitação do diagnóstico e tenham uma melhor adaptação ao tratamento. A família é a base motivadora e facilitadora em que a mulher possa aderir ao tratamento e enfrentar os seus temores relacionados à doença, aumentando a expectativa de vida e a possibilidade de seguir com os planos para o futuro.

A religiosidade também se faz importante nesse processo, pois atua como um fator crucial produzindo conforto e esperança nas mulheres, que veem no sagrado o consolo para suas angústias. Por fim, o trabalho, que além de ser uma maneira de se manter financeiramente, é também o local onde a mulher poderá mostrar suas habilidades, continuar sentindo-se útil, eliminando assim, pensamentos e sentimentos que surgem com o diagnóstico da doença.

Contanto, para que as mulheres enfrentem a vivência com o HIV/AIDS como uma doença que possibilita a continuidade da vida na sociedade é necessário que o aconselhamento, ou seja, o primeiro contato desta mulher após o diagnóstico seja com profissionais de saúde capacitados, pois isso influenciará em todo o processo de adaptação com a realidade.

\section{Referências}

1. Brasil. Ministério da Saúde - Secretaria de Vigilância em Saúde - Departamento de DST, AIDS e Hepatites virais. Boletim Epidemiológico Aids e DST. Brasília: Ministério da saúde; 2014.

2. Val LF,NichiataLYI. A integralidade e a vulnerabilidade programática às DST/HIV/AIDS na Atenção Básica. RevEscEnferm USP. 2014; 48(Esp): 145-51.

3. Oltamari LC, Otto LS. Conjugalidade e AIDS: um estudo sobre a infecção entre casais. Psicol. Soc. 2006; 18 (3): 55-61.

4. Sousa MCP, Santo ACGE, Motta SKA. Gênero, vulnerabilidade das mulheres ao HIV/AIDS e ações de prevenção em bairro da 
periferia de Teresina, Piauí, Brasil. Saúde Soc. 2008; 17 (2): 58-68.

5. Carvalho CML, Galvão MTG. Enfrentamento da AIDS entre mulheres infectadas em Fortaleza - CE. RevEscEnferm USP. 2008; 42 (1):90-7.

6. Renesto HMF, Falbo AR, Souza $E$, Vasconcelos, MG. Enfrentamento e percepção da mulher em relação à infecção pelo HIV. Rev. Saúde Públ. 2014; 48(1): 36-42.

7. Costa $P$,Leite RCBO. Estratégias de enfrentamento utilizadas pelos pacientes oncológicos submetidos a cirurgias mutiladoras. Rev. bras.cancerol. 2009; 55(4): 355-64.

8. Sampaio R, Mancine M. Estudos de Revisão Sistemática: um guia para síntese. Rev. Bras. de Fisioter. 2007; 11(1): 83-9.

9. Carvalho CML, Galvão MTG, Silva RM. Alterações na vida de mulheres com Síndrome da Imunodeficiência Adquirida em face da doença. Acta Paul Enferm. 2010; 23 (1): 94-100.

10. Félix G, Ceolim MF. O perfil da mulher portadora de HIV/AIDS e sua adesão à terapêutica antirretroviral. RevEscEnferm USP. 2012;46(4): 884-91.

11. Selli L, Cechim PL. Mulheres HIV/Aids: silenciamento, dor moral e saúde coletiva. RevistaBioética. 2006; 14(1): 17-26.

12. Nascimento AMG, Barbosa CS, Medrado B. Mulheres de Camaragibe representação social sobre a vulnerabilidade feminina em tempos de AIDS. Rev. Bras. Saude Mater. Infant. 2005; 5(1): 77-86.

13. Ferreira RMC, Figueredo MAC. Reinserção no mercado de trabalho. Barreiras e silêncio no enfrentamento da exclusão por pessoas com HIV/AIDS. Medicina(Ribeirão Preto). 2006; 39(4): 591- 600.

14. Moreira V, Bloc L, Rocha M. Significados da finitude no mundo vivido de pessoas com HIV/AIDS: um estudo fenomenológico. Estud. pesq. psicol. 2012; 12(2): 554-71.

15. Martins JT, Guaranhani ML, Robazzi MLCC, Santos WC. Significados de qualidade de vida para mulheres convivendo com a AIDS. Rev. Gaúcha Enferm. (Online) 2008; 29(4): 619-25.

16. Centro de Referência Técnica em Psicologia e Políticas Públicas - CREPOP. Referências técnicas para atuação do(a) psicólogo(a) nos programas de DST e AIDS. Brasília: Conselho Federal de Psicologia (CFP); 2008.
17. Galvão MTG, Paiva SDS. Vivências para o enfrentamento do HIV entre mulheres infectadas pelo vírus. RevBrasEnferm. 2011; 64(6): 1022-7.

18. Ferreira RCM, Figueredo MAC, Souza LB. Trabalho, HIV/AIDS: Enfrentamento e dificuldades relatadas por mulheres. Psicol. estud. 2011; 16(2): 259-67.

19. Reis AL, Xavier IDM. Mulher e Aids: rompendo o silêncio de adesão. RevBrasEnferm. 2003; 56(1): 28-4.

\section{Endereço para Correspondência}

Universidade Federal da Bahia UFBA

e-mail: teciamarya@yahoo.com.br

Recebido em 03/04/2017

Aprovado em 10/08/2017

Publicado em 21/08/2017 